Article

\title{
De Novo Assembly Discovered Novel Structures in Genome of Plastids and Revealed Divergent Inverted Repeats in Mammillaria (Cactaceae, Caryophyllales)
}

\author{
Sofía Solórzano ${ }^{1, *(\mathbb{D}}$, Delil A. Chincoya ${ }^{1}$, Alejandro Sanchez-Flores ${ }^{2, *}$, Karel Estrada $^{2}$, \\ Clara E. Díaz-Velásquez ${ }^{3}$, Antonio González-Rodríguez ${ }^{4}$, Felipe Vaca-Paniagua ${ }^{3,5}$, \\ Patricia Dávila ${ }^{6}$ and Salvador Arias ${ }^{7}$ \\ 1 Laboratorio de Ecología Molecular y Evolución, UBIPRO, FES Iztacala, Universidad Nacional Autónoma de \\ México, Avenida de los Barrios 1, Los Reyes Iztacala, Tlalnepantla de Baz 54090, Estado de México, Mexico; \\ dela@comunidad.unam.mx \\ 2 Unidad Universitaria de Secuenciación Masiva y Bioinformática, Instituto de Biotecnología, Universidad \\ Nacional Autónoma de México, Avenida Universidad 2001, Chamilpa, Cuernavaca 62250, Mexico; \\ karel@ibt.unam.mx \\ 3 Laboratorio Nacional en Salud: Diagnóstico Molecular y Efecto Ambiental en Enfermedades \\ Crónico-Degenerativas, FES Iztacala, Universidad Nacional Autónoma de México, Los Reyes Iztacala, \\ Tlalnepantla de Baz 54090, Estado de México, Mexico; cdiaz@comunidad.unam.mx (C.E.D.-V.); \\ Felipe.vaca@iztacala.unam.mx (F.V.-P.) \\ 4 Laboratorio de Genética de la Conservación, Instituto de Investigaciones en Ecosistemas y Sustentabilidad, \\ Universidad Nacional Autónoma de México, Antigua carretera a Pátzcuaro 8701, Ex-Hacienda San José La \\ Huerta, Morelia 58190, Michoacán, Mexico; agrodrig@cieco.unam.mx \\ 5 Subdirección de Investigación Básica, Instituto Nacional de Cancerología, Ciudad de México 04510, Mexico \\ 6 Laboratorio de Recursos Naturales, UBIPRO, FES Iztacala, Universidad Nacional Autónoma de México, \\ Avenida de los Barrios 1, Los Reyes Iztacala, Tlalnepantla de Baz 54090, Estado de México, Mexico; \\ pdavilaa@unam.mx \\ 7 Jardín Botánico, Instituto de Biología, Universidad Nacional Autónoma de México, Tercer Circuito Exterior, \\ Ciudad Universitaria, Coyoacán, Ciudad de México 04510, Mexico; sarias@ib.unam.mx \\ * Correspondence: solorzanols@unam.mx (S.S.); alexsf@ibt.unam.mx (A.S.-F.)
}

Received: 21 August 2019; Accepted: 22 September 2019; Published: 1 October 2019

check for updates

\begin{abstract}
The complete sequence of chloroplast genome (cpDNA) has been documented for single large columnar species of Cactaceae, lacking inverted repeats (IRs). We sequenced cpDNA for seven species of the short-globose cacti of Mammillaria and de novo assembly revealed three novel structures in land plants. These structures have a large single copy (LSC) that is 2.5 to 10 times larger than the small single copy (SSC), and two IRs that contain strong differences in length and gene composition. Structure 1 is distinguished by short IRs of $<1 \mathrm{~kb}$ composed by rpl23-trnI-CAU-ycf2; with a total length of $110,189 \mathrm{bp}$ and 113 genes. In structure 2, each IR is approximately $7.2 \mathrm{~kb}$ and is composed of 11 genes and one Intergenic Spacer-( $p s b K$-trnQ)-trnQ-UUG-rps16-trnK-UUU-matK-trnK-UUU-psbA-trnH-GU G-rpl2-rpl23-trnI-CAU-ycf2; with a total size of 116,175 bp and 120 genes. Structure 3 has divergent IRs of approximately $14.1 \mathrm{~kb}$, where IRA is composed of 20 genes: psbA-trnH-GUG-rpl23-trnI-CAUycf2-ndhB-rps7-rps12-trnV-GAC-rrn16-ycf68-trnI-GAU-trnA-AGC-rrn23 -rrn4.5-rrn5-trnR-ACG-trnNGUU-ndhF-rpl32; and IRB is identical to the IRA, but lacks rpl23. This structure has 131 genes and, by pseudogenization, it is shown to have the shortest cpDNA, of just 107,343 bp. Our findings show that Mammillaria bears an unusual structural diversity of cpDNA, which supports the elucidation of the evolutionary processes involved in cacti lineages.
\end{abstract}

Keywords: divergent inverted repeats; short-globose cacti; novel gene rearrangements; pseudogenization 


\section{Introduction}

A new era in the study of evolutionary processes of chloroplasts and their genomes has arisen with the advent of massive sequencing [1]. Huge advances have been documented since 1883, when Schimper postulated an endosymbiotic cyanobacterial origin of these organelles [2]. More recently, many studies have focused on determining the cyanobacterial origin of the DNA molecule contained in chloroplasts $[1,3,4]$. Using comparative genomics, DNA sequences of complete genomes of contemporary cyanobacteria, algae, and plants have been analyzed, leading to the discovery that the chloroplast genome encompasses structural changes with significant evolutionary information. Thus, in comparison to cyanobacteria and algae, a significant reduction in the total length and in the number of genes has been documented in land plants [5]. However, many genes lacking in the chloroplast genome have migrated to nuclear or mitochondrial genomes [6], which indicates a complex functional relationship among the three genomes contained in plants. In addition, in plants, the chloroplast genome has a hybrid transcriptional process, which denotes the evolutionary transition from a prokaryotic form to a eukaryotic form. Accordingly, most encoding regions are regulated in operons which are transcribed into polycistronic units, as occurs in contemporary cyanobacteria [7]. Additionally, typical eukaryotic transcriptional regulation was documented in nearly 60 promoters for encoding regions and their transfer RNAs [8].

Comparisons within land plants have concluded that the differences in the total length of the complete chloroplast genome (cpDNA) are caused by lengthening or shortening of genes and not by a significant gain/loss of them [5,9]. Flowering land plants tend to have a total of 120 genes; of these, nearly 80 are encoding genes, 30 are tRNAs, and four are rRNAs [9]. In angiosperms, these genes are not randomly distributed along the entire molecule of DNA of the chloroplasts, but instead determine a recognizable structure in the cpDNA. Moreover, in most angiosperms, this cpDNA is sectioned into four regions, which are distinguished by their length and trend in gene composition. The largest single copy (LSC) contains most of the encoding genes directly related to photosystems I and II, ATP synthases, proteins of cytochrome b/f complex, DNA depending on RNA polymerases, and proteins which tend to have a single encoding gene: ribulose bisphosphate carboxylase large chain, maturase $\mathrm{K}$, envelope membrane protein, acetyl coenzyme carboxylase, transcriptional initiation factor, as well as most of proteins of small and large subunits of the ribosome. The small single copy (SSC) often contains dehydrogenase subunits and open reading frames. This copy typically shows the highest mutation rates. The SSC is often flanked by two inverted repeats (IRA and IRB), which vary in gene composition and length [1]. In these plants, the IRs typically contains four ribosomal RNA subunits $(4.5 S, 5 S, 16 S$, and 23S) and five transfer RNA subunits (trnA-UGC, trnI-GAU, trnN-GUU, trnR-ACG, and $\operatorname{trn} V$-GAC). In addition, the IRs exhibit lower mutation rates than the SSC [10]. Currently, nearly $500 \mathrm{cpDNA}$ have been sequenced for the land plant group, showing that IRs are the main source of structural variation by relative expansion, contraction, and gene rearrangement. However, between IRA and IRB within the same genome, there are no differences in gene arrangement and composition, and in only a few cases do they have low divergence in the DNA sequence $[9,10]$.

In angiosperms, although IRs are commonly present, they are absent in some taxa. Around 95\% of legume species of the subfamily Papilionoideae (order Fabales) lack IRs, which has been interpreted as a novel evolutionary change that appeared in a common ancestor and, eventually, was inherited by its descendants, whereas other legume species of this order have IRs [11]. Recently, the lack of IRs was documented in two species of large columnar cacti of Cactoideae (Cactaceae, Caryophyllales) of the tribe Echinocereeae. The loss of IRs in the saguaro (Carnegiea gigantea) was interpreted as a novel structural change [12]. In addition, we have verified that the cpDNA of Pachycereus schottii, which has recently been directly submitted to the GenBank database, also lacks IRs (uploaded with its synonym Lophocereus schottii, NCBI, NC_041727.1). In contrast, in all other species currently sequenced in Caryophyllales have been shown to have IRs [13]. At the infrageneric level, contrasting results have been documented and it is not a rule that all members of a certain genus show identical cpDNA structure. For example, in 13 species of Camellia (Theaceae, Ericales), identical structure of cpDNA and 
low divergence of DNA sequences were documented [14]. A similar result was obtained for seven species of Silene (Caryophyllaceae, Caryophyllales), with identical cpDNA structure and only a small gain/loss of genes among them being documented $[15,16]$. In contrast, unusual results have been obtained for 17 species of Erodium (Geraniaceae, Geraniales), which showed deep and strong structural changes, such as expansion and contraction of IRs or even the absence of IRs, and substantial gene rearrangements in the LSC [17]. Thus, data based on characterizations of the structures of complete chloroplast genomes are necessary, as they might reveal novel unexpected results that may help to clarify evolutionary processes in plants.

In this study, we focused on cacti species of the short-globose genus Mammillaria (Cactoideae, tribe Cacteae). Mammillaria is relevant, in terms of biodiversity, due to its high species richness (163-232) [18] in the Cactaceae. A total of 192 species and subspecies of Mammillaria are listed in the Red List of Threatened Species of International Union for Conservation of Nature [19]. For the species of this genus, non-fully resolved phylogenies were obtained from DNA sequences of the rpl16 intron and psbA-trnH intergenic spacer regions of the chloroplast [20]. The increment of plastid molecular markers (rpl16, trnK, and rpoC1 introns, and trnK-psbA, rpl20-rps12, trnL-trnF, and trnT-trnL intergenic spacers) did not resolve the relationships among species of Mammillaria, nor of species from closer genera (i.e., Coryphantha, Escobaria, Neolloydia, Ortegocactus, and Pelecyphora). These unresolved evolutionary relationships have been attributed to the recent origin of Cactaceae (e.g., [21,22]), estimated at 35 million years ago [23]. Currently, morphological characteristics have been used to postulate the taxonomic limits among species of Mammillaria and of those in close cacti genera [18]. However, these characters are ambiguous and often do not accomplish a robust taxonomically resolved separation [20,21].

In this study, we de novo assembled the complete chloroplast genome of seven species in this genus, in order to utilize these genomes as reference for Mammillaria. A second objective was to identify putative structural characteristics of the cpDNA of Mammillaria, by comparing with the complete chloroplast genomes, which have been documented for other cacti species and other Caryophyllales. In addition, we discuss whether the structural differences of the cpDNA discovered in Mammillaria may serve to resolve the evolutionary and taxonomic pendants of this genus. As structural differences have been documented at the subfamily level, we expect the cpDNA of Mammillaria (Cacteae) to differ from those of the large columnar cacti (Echinocereeae); however, among species of Mammillaria, structural differences in cpDNA are not expected by its recent divergence.

\section{Results}

\subsection{Gene Composition and Length Variation in Three Novel cpDNA Structures Identified in Mammillaria}

De novo assembly revealed three structures of cpDNA in Mammillaria (Figure 1). Structure 1 was present in M. albiflora and M. pectinifera (Figure 1a), structure 2 in M. crucigera, M. huitzilopochtli, M. solisioides, and M. supertexta (Figure 1b), and structure 3 in M. zephyranthoides (Figure 1c). These structures had a quadripartite partition, into LSC, SSC, and two IRs (Figure 1). We identified unexpected and strong structural differences in gene composition and length among the three structures (Figures 2 and $3 a$ ). In addition, structure 3 (M. zephyranthoides) had divergent IRs; meanwhile, the rest of the species had identical gene composition in their IRs (Figure 1).

Variation between species in the total length and number of genes of cpDNA were documented (Tables 1 and 2). The cpDNA of Mammillaria ranged from 107,343 bp (M. zephyranthoides) to 116,175 bp (M. supertexta) (Table 1). The relative length of LSC represented approximately $62 \%$ of the genome in the six species (M. albiflora, M. crucigera, M. huitzilopochtli, M. pectinifera, M. solisioides, and M. supertexta) (Table 1). Moreover, the LSC was nearly 2.5 times larger than SSC, which represented 25.35-28\% of the total genome length (Table 1). In contrast, in M. zephyranthoides, the LSC was longer $(68 \%$ of the cpDNA length), being 10 times larger than its respective SSC, whose length only reached 7\%. The shortening of SSC in M. zephyranthoides was due to the lengthening of the IRs, which had nearly $14 \mathrm{~kb}$, 
and to the strong reduction of the genes $y c f 1$ and $y c f 2$ to $<1 \mathrm{~kb}$; meanwhile, in the other species of Mammillaria, these genes were $>6 \mathrm{~kb}$ (Figure 1, Table 1).

We identified additional different types of gene rearrangements at the LSC (Figure 3b). The first was a type of rearrangement involving blocks of genes, which were inverted but maintained identical order (Figure $3 b$ ); there was also a second type involving a single gene with two variants: (a) the single gene did not change its relative location, but its orientation was inverted (trnF-GAA); (b) the single gene changed in location, but it maintained its orientation ( $r p l 2)$. The single gene $\operatorname{trnF-GAA}$ had identical orientation in the species of structure 1 (M. albiflora and M. pectinifera), structure 3 ( $M$. zephyranthoides), and $M$. solisioides of structure 2, but was inverted in the other three species of structure 2 (M. crucigera, M. huitzilopochtli, and M. supertexta). In the structure 1 species, rpl2 flanked the IRA in M. pectinifera, whereas, in M. albiflora, it flanked the IRB. In addition, in M. supertexta (structure 2) and M. zephyranthoides (structure 3), rpl33 was lost, but it was present in the other five species of Mammillaria as pseudogene except in M. albiflora (Figure 1, Table 2).

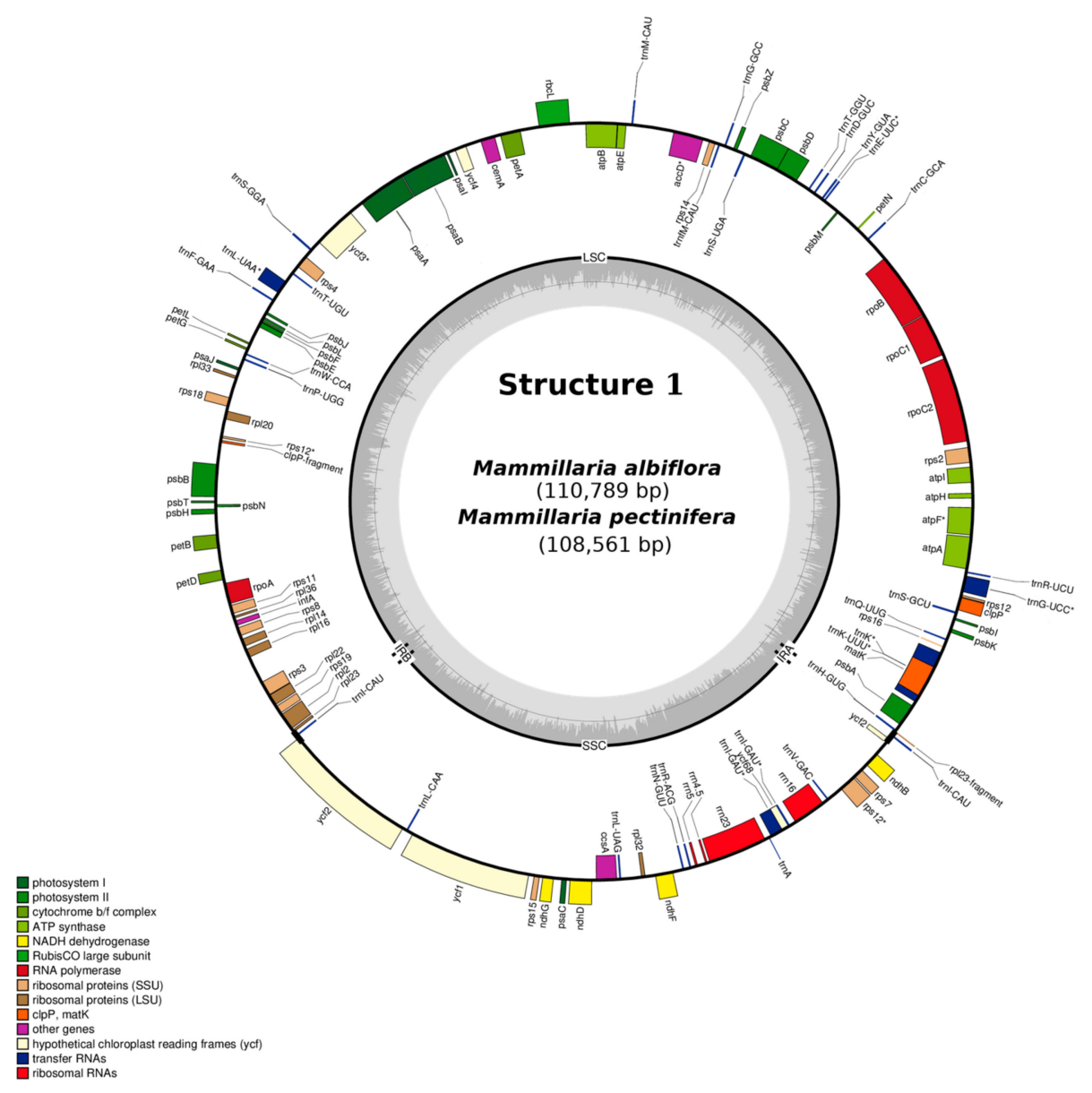

(a)

Figure 1. Cont. 


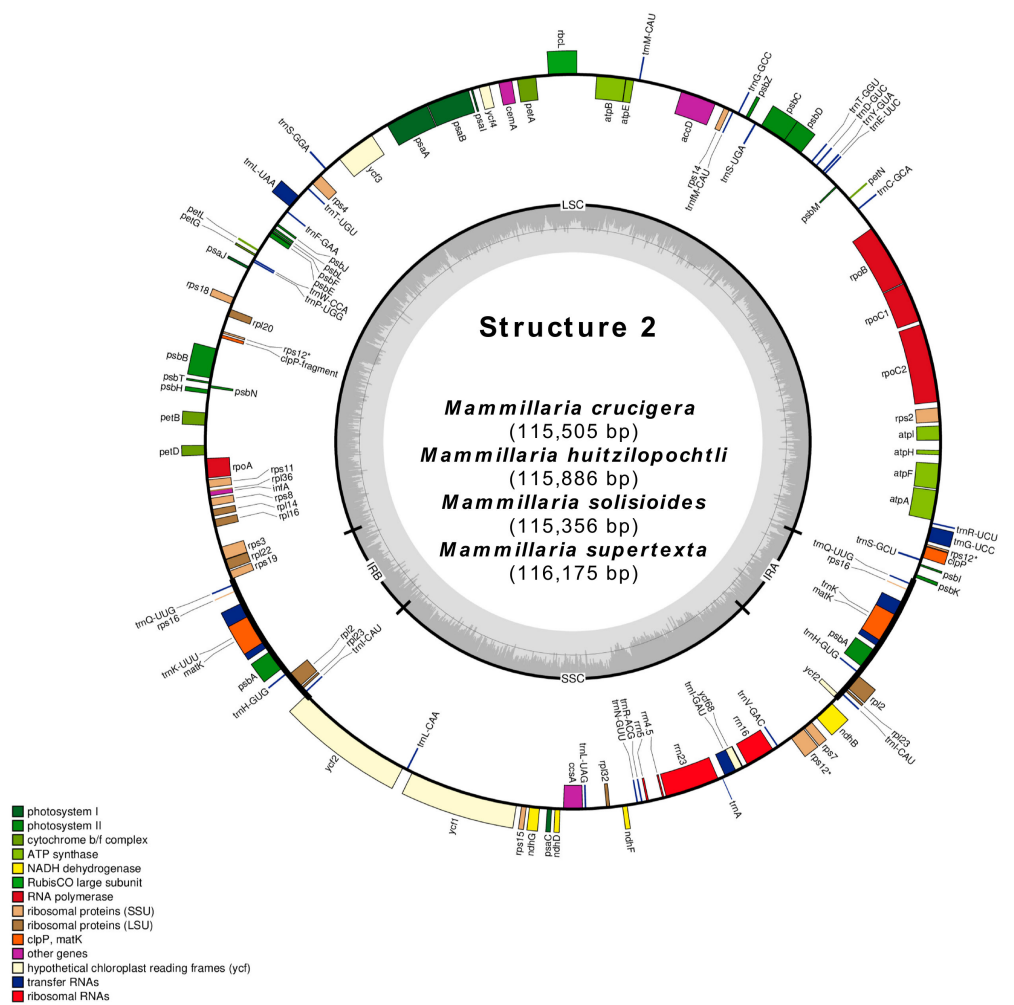

(b)

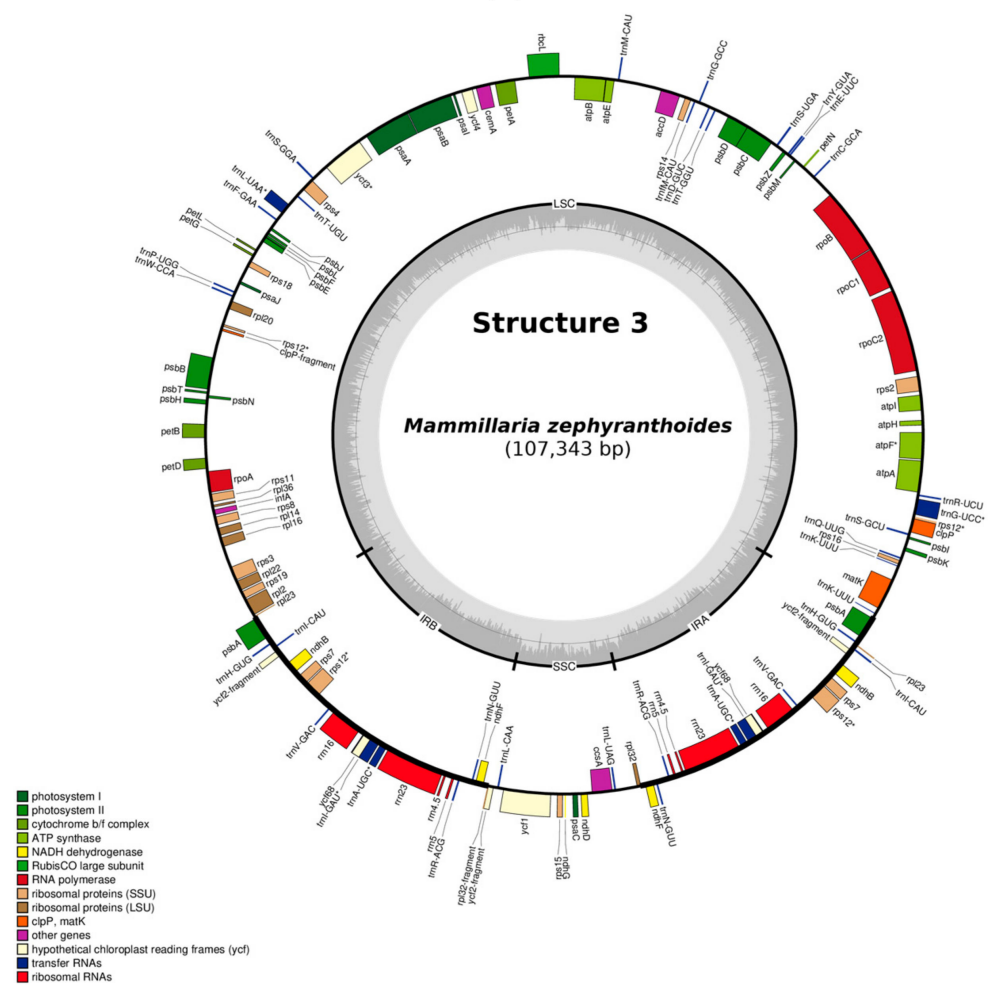

(c)

Figure 1. Three different structures found in the complete chloroplast genome of Mammillaria: (a) structure 1, (b) structure 2, and (c) structure 3. In structure 1, the rpl2 gene is flanking IRB in M. albiflora and IRA in M. pectinifera. Gene rpl33 was lost in M. supertexta of structure 2 and in M. zephyranthoides of structure 3. The genomes are displayed circularly, and IRA and IRB correspond to duplicated blocks of regions; starting from the top of the circle, the IRA is the one that appears first in clockwise. 
On the other hand, comparison of the complete genomes of the seven species showed similar percentages of types of genes. In the three structures, the highest percentage of genes corresponded to tRNAs (26\%), where each of the sets of $r p s$ and $p s b$ represented $13 \%$ of the genes. Another similarity found among species was that, in the LSC, large blocks of concatenated genes maintained identical gene compositions and arrangements (Figures 1 and 2). Most of the concatenated genes correspond to the encoding genes of photosystems I and II. In addition, the $r b c L$ gene, units of the cytochrome $\mathrm{b} / \mathrm{f}$ complex, and genes of the DNA-dependent RNA polymerase (Table 2) were identical in number, location, and arrangement (Figure 1). Comparisons of LSC and SSC showed that structures 1 and 2 had more mutual similarities than either had with structure 3 (Table 2). In the SSC, the seven species maintained identical order and orientation in ycf2-trnL-CAA-ycf1; although, in structure 3, they were shorter by pseudogenization (Figure 1).

In addition, in the seven species pseudogenization was identified in the NADH dehydrogenase-like (NDH) complex of plastid genes (ndh genes, hereafter). Of this family of genes, only four subunits of the suite of dehydrogenase genes $(\mathrm{B}, \mathrm{D}, \mathrm{F}$, and $\mathrm{G})$ were recorded in the seven species. The $n d h$ subunits $B, D$, and $F$ were pseudogenes in the seven species, and subunit $G$ was pseudogene only in M. pectinifera, $M$. solisioides and M. zephyranthoides. In addition, ycf68 was a pseudogene in all seven species, and ycf4 was pseudogene in three species except in M. albiflora, M. huitzilopochtli, M. supertexta and M. zephyranthoides (Table 2).

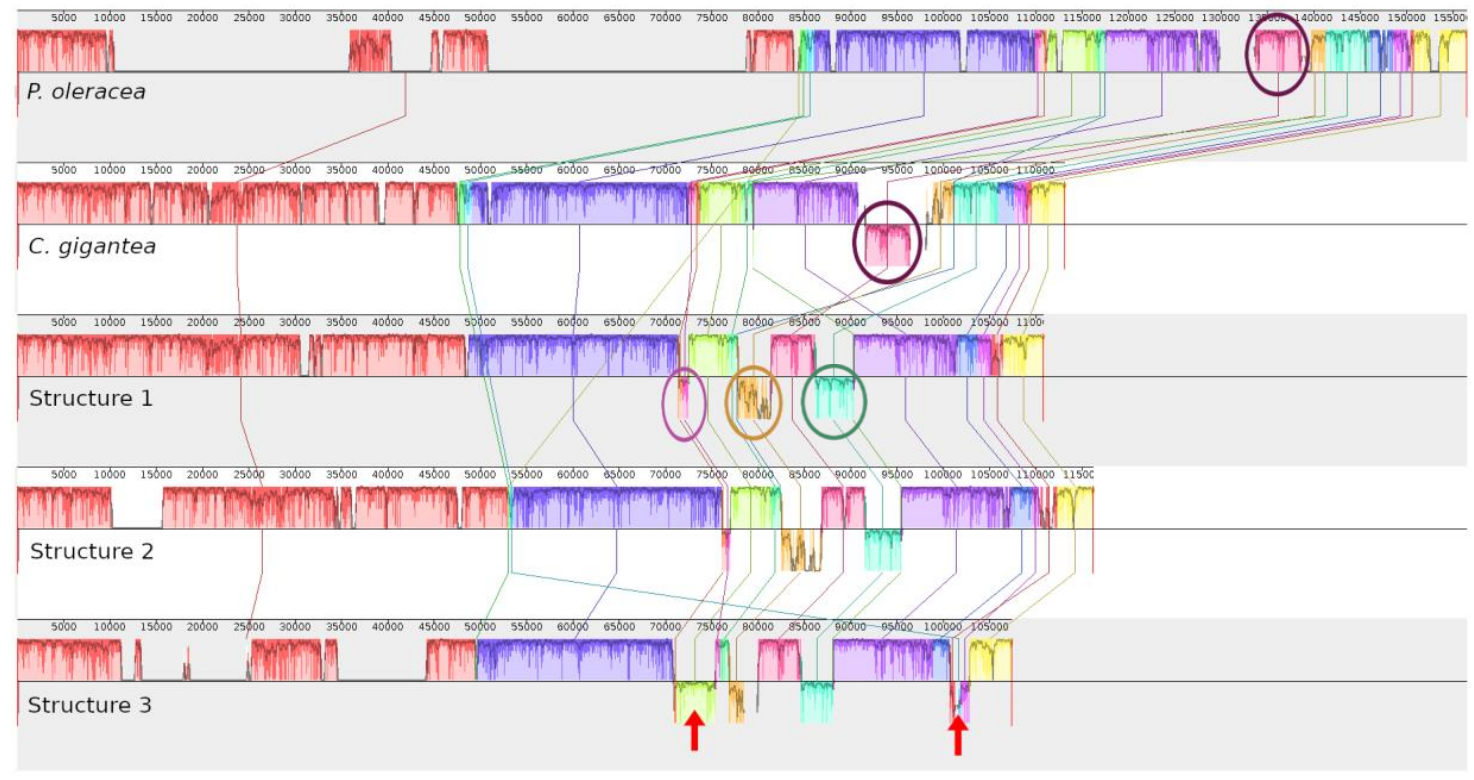

Figure 2. MAUVE graphic of five structural alignments of complete chloroplast genomes. The upper graph corresponds to caryophyllid P. oleracea (Portulacaceae); below that, the large giant columnar cactus, C. gigantea; and the last three graphs are the three structures documented in Mammillaria. Relative inverted DNA sequences are drawn above/below of the horizontal line; identical genes are in the same color. P. oleracea has a larger genome than any species of Cactaceae. Discarding the IRs that are recorded in Mammillaria and P. oleracea, but not in C. gigantea, the cpDNA structure of P. oleracea is more similar in structure to C. gigantea than to Mammillaria. Between C. gigantea and P. oleracea, a single large block of inverted genes (encircled) corresponding to atpB and atpE is shown. This block of genes in Mammillaria has identical orientation to P. oleracea. In Mammillaria, many other novel gene rearrangements, which are absent in the other two-caryophyllid taxa, were documented. Additionally, structure 3 has two blocks of inverted genes (described in detail in Figure 3b), with respect to structures 1 and 2. These two blocks of genes are indicated with arrows and have identical orientation in $C$. gigantea, P. oleracea, and structures 1 and 2 of Mammillaria. 


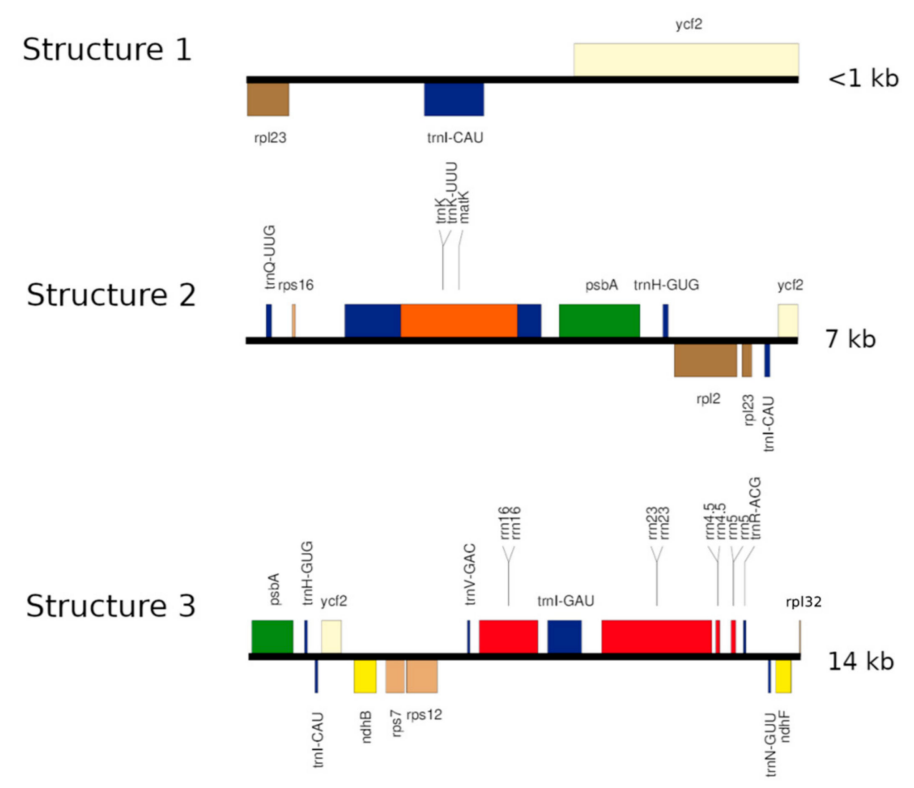

(a)
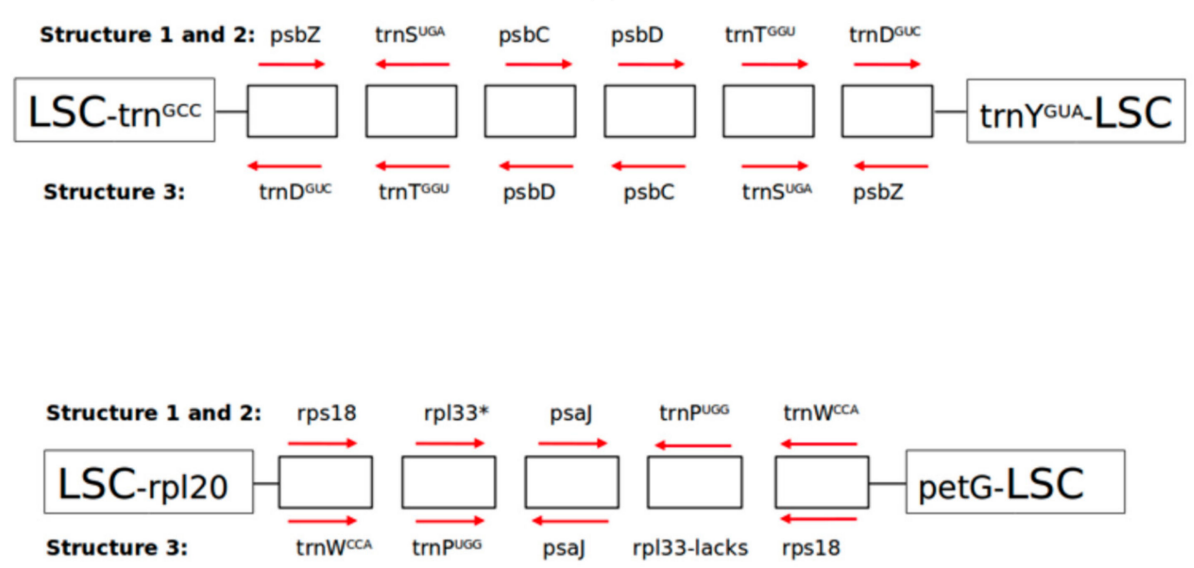

(b)

Figure 3. (a) Comparison of length and gene composition of IRs in the three structures documented for the complete chloroplast genomes of Mammillaria. The two IRs of structure 3 diverge in rpl23; its location in IRA is denoted with an asterisk. (b) Blocks of genes rearranged at the LSC. These genes are inverted and reoriented in structures 1 and 2, with respect to structure 3 . The direction of the row indicates the orientation of transcription, to the left in sense of clockwise and to the right, counter-clockwise. The large squares indicate the genes of LSC that flank these two rearrangements. The asterisk in rpl33 (bottom figure) indicates that, in M. supertexta of structure 2 and in species of structure 3 , this gene was lost. 
Table 1. Species of Mammillaria grouped by the type of the structure identified in the complete chloroplast genome (cpDNA). Within and among structure variation in total length size, the two inverted repeats (IRs), large single copy (LSC), and small single copy (SSC) were detected.

\begin{tabular}{ccccccc}
\hline Type of Structure & Total Length & IRs & LSC & SCC & Total Number of Genes & Access Number ${ }^{1}$ \\
\hline I. Structure 1 & & & & & & \\
1.1 M. albiflora & 110789 & 1348 & 78380 & 31061 & 113 & MN517610 \\
1.2. M. pectinifera & 108561 & 1544 & 72273 & 29744 & 113 & MN519716 \\
II. Structure 2 & & & & & & \\
1. M. crucigera & 115505 & 14522 & 71565 & 29418 & 120 & MN517613 \\
2. M. huitzilopochtli & 115886 & 14488 & 71997 & 29401 & 120 & MN517612 \\
3. M. solisioides & 115356 & 14428 & 7169029238 & 120 & MN518341 \\
4. M. supertexta & 116175 & 144907224029445 & 119 & MN508963 \\
III. Structure 3 & & & & & 131 & MN517611 \\
1. M. zephyranthoides & 107343 & 28252 & 718117281 & & \\
\hline
\end{tabular}

${ }^{1}$ GeneBank access number of the DNA sequences deposited.

Table 2. Variation in structural and functional gene composition in the three structures of cpDNA found in Mammillaria. A total of 18 different types of genes were documented, and these are organized alphabetically according to their location in IRs, LSC, and SSC. All the genes located at IRs are duplicated

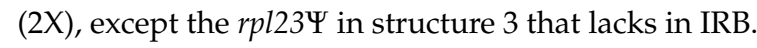

\begin{tabular}{|c|c|c|c|c|}
\hline $\begin{array}{c}\text { Gene } \\
\text { Type/Structure }\end{array}$ & Region & Structure 1 & Structure 2 & Structure 3 \\
\hline \multirow[t]{2}{*}{$\begin{array}{l}\text { 1. Ribosomal RNA } \\
\text { (rrn) }\end{array}$} & SSC & $\operatorname{rrn} 4.5,5,16,23$ & $\operatorname{rrn} 4.5,5,16,23$ & \\
\hline & IRs & & & $\operatorname{rrn} 4.5,5,16,23(2 X)$ \\
\hline \multirow[t]{3}{*}{$\begin{array}{l}\text { 2. Transfer RNA } \\
\text { (trn) }\end{array}$} & LSC & 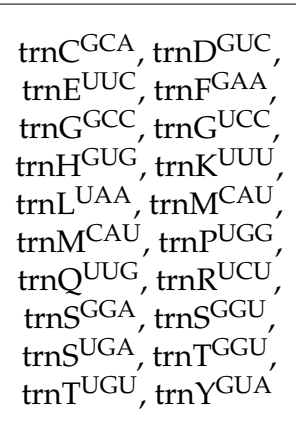 & 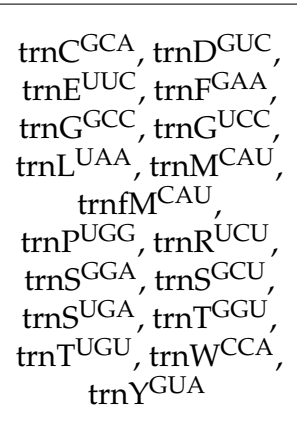 & 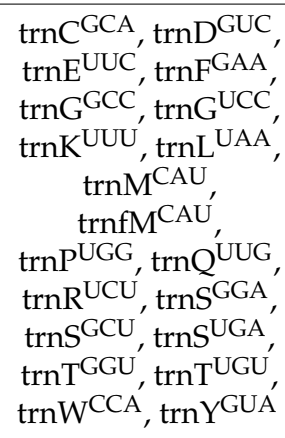 \\
\hline & SSC & 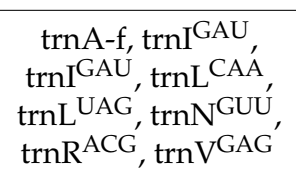 & $\begin{array}{l}\operatorname{trn} A-f, \operatorname{trn} I^{G A U}, \\
\operatorname{trnI} I^{U A G}, \operatorname{trn} N^{G U U}, \\
\operatorname{trnL}{ }^{C A A}, \operatorname{trnR}{ }^{A C G}, \\
\operatorname{trn}^{G A G}\end{array}$ & $\operatorname{trn} L^{\mathrm{UAG}}, \operatorname{trn} \mathrm{L}^{\mathrm{CAA}}$ \\
\hline & IRs & $\operatorname{trnI} I^{C A U}(2 X)$ & $\begin{array}{l}\operatorname{trn} \mathrm{H}^{\mathrm{GUG}}, \mathrm{tmI}^{\mathrm{CAU}} \\
\operatorname{trnK} \mathrm{K}^{\mathrm{UUU}}, \operatorname{trn}^{\mathrm{UUG}} \\
(2 \mathrm{X})\end{array}$ & $\begin{array}{c}\operatorname{trn} \mathrm{A}^{\mathrm{UGC}}, \operatorname{trnH}^{\mathrm{GUG}}, \\
\operatorname{trnI} \mathrm{I}^{\mathrm{CAU}}, \operatorname{trn} \mathrm{I}^{\mathrm{GAU}}, \\
\operatorname{trn} \mathrm{N}^{\mathrm{GUU}}, \operatorname{trn}^{\mathrm{ACG}}, \\
\operatorname{trn} \mathrm{V}^{\mathrm{GAC}}(2 \mathrm{X})\end{array}$ \\
\hline \multirow[t]{3}{*}{$\begin{array}{l}\text { 3. Proteins of small } \\
\text { subunits of the } \\
\text { ribosome (rps) }\end{array}$} & LSC & $\begin{array}{c}\operatorname{rps} 2,3,4,8,11,12 \\
(2), 14,16 \Psi, 18 \Psi, 19\end{array}$ & $\begin{array}{c}\operatorname{rps} 2,3,4,8,11,12 \\
(2), 14,18 \Psi, 19\end{array}$ & $\begin{array}{c}\text { rps2, 3, 4, 811, 12, } \\
12 \Psi, 14,16 \Psi, 18 \Psi \\
19\end{array}$ \\
\hline & SSC & rps7, 12,15 & rps7, 12,15 & rps15 \\
\hline & IRs & & $\operatorname{rps} 16 \Psi(2 X)$ & rps7, $12,(2 X)$ \\
\hline
\end{tabular}


Table 2. Cont.

\begin{tabular}{|c|c|c|c|c|}
\hline $\begin{array}{c}\text { Gene } \\
\text { Type/Structure }\end{array}$ & Region & Structure 1 & Structure 2 & Structure 3 \\
\hline \multirow[t]{3}{*}{$\begin{array}{l}\text { 4. Proteins of large } \\
\text { subunits of the } \\
\text { ribosome (rpl) }\end{array}$} & LSC & $\begin{array}{c}\mathrm{rpl} 2,14,16,20,22 \\
33 \Psi, 36 \Psi\end{array}$ & $\begin{array}{c}\operatorname{rpl14}, 16 \Psi, 20, \\
22,33 \Psi^{*}, 36 \Psi\end{array}$ & $\begin{array}{c}\mathrm{rpl} 2,14,16 \Psi, 20,22, \\
23 \Psi, 36\end{array}$ \\
\hline & SSC & $\operatorname{rpl} 32$ & rpl32 & \\
\hline & IRs & $\operatorname{rpl} 23 \Psi(2 X)$ & $\operatorname{rpl} 2,23 \Psi(2 X)$ & $\begin{array}{c}\mathrm{rpl} 32(2 \mathrm{X}), 23 \Psi \\
\text { (IRA) }\end{array}$ \\
\hline $\begin{array}{l}\text { 5. DNA dependent } \\
\text { RNA polymerase } \\
\text { (rpo) }\end{array}$ & LSC & rpoA, B, C1, C2 & $\operatorname{rpoA}, \mathrm{B}, \mathrm{C} 1, \mathrm{C} 2$ & rpoA, B, C1, C2, \\
\hline \multirow[t]{2}{*}{$\begin{array}{l}\text { 6. NADH } \\
\text { dehydrogenase } \\
\text { (ndh) }\end{array}$} & SSC & $\begin{array}{c}\operatorname{ndhB\Psi }, \mathrm{D \Psi}, \mathrm{F \Psi} \\
\mathrm{G \Psi} \Psi^{* * *}\end{array}$ & $\operatorname{ndhB\Psi } \underset{* * *}{\mathrm{D} \Psi}, \mathrm{F \Psi}, \mathrm{G}$ & \\
\hline & IRs & & & 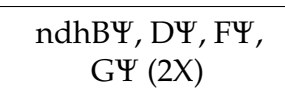 \\
\hline \multirow[t]{2}{*}{$\begin{array}{l}\text { 7. Photosystem I } \\
\text { (psa) }\end{array}$} & LSC & psaA, B, I, J & psaA, B, I, J & psaA, B, I, J \\
\hline & SSC & psaC & psaC & psaC \\
\hline $\begin{array}{l}\text { 8. Photosystem II } \\
\text { (psb) }\end{array}$ & LSC & $\begin{array}{c}\text { psbA, B, C, D, E, F, } \\
\text { H, I, J, K, L, M, N, T, } \\
\text { Z }\end{array}$ & $\begin{array}{l}\text { psbB, C, D, E, F, H, } \\
\text { I, J, K, L, M, N, T, Z }\end{array}$ & $\begin{array}{l}\text { psbB, C, D, E, F, H, } \\
\text { I, J, L, K, M, N T, Z }\end{array}$ \\
\hline & IRs & & psbA (2X) & $\operatorname{psbA}(2 X)$ \\
\hline $\begin{array}{l}\text { 9. Cytochrome b/f } \\
\text { complex (pet) }\end{array}$ & LSC & $\operatorname{petA}, \mathrm{B}, \mathrm{D}, \mathrm{G}, \mathrm{L}, \mathrm{N}$ & $\operatorname{pet} A, B, D, G, L, N$ & $\operatorname{pet} A, B, D, G, L, N$ \\
\hline $\begin{array}{l}\text { 10. ATP synthase } \\
\text { (atp) }\end{array}$ & LSC & $\operatorname{atpA}, B, E, F, H, I$ & $\operatorname{atpA}, B, E, F, H, I$ & $\operatorname{atpA}, B, E, F, H, I$ \\
\hline 11. Rubisco (rbc) & LSC & $\mathrm{rbcL}$ & $\mathrm{rbcL}$ & $\mathrm{rbcL}$ \\
\hline \multirow[t]{2}{*}{ 12. Maturase $\mathrm{K}$} & LSC & matK & & matK \\
\hline & IRs & & $\operatorname{matK}(2 X)$ & \\
\hline 13. Protease (clp) & LSC & $\operatorname{clpP} \Psi, \operatorname{clpP}$ & $\operatorname{clpP\Psi }, \operatorname{clpP}$ & 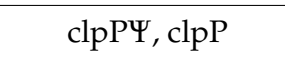 \\
\hline $\begin{array}{l}\text { 14. Envelope } \\
\text { membrane protein } \\
\text { (cem) }\end{array}$ & LSC & cemA & cemA & cemA \\
\hline $\begin{array}{l}\text { 15. Subunit of } \\
\text { acetil-CoA-carboxylase } \\
\text { (acc) }\end{array}$ & LSC & $\operatorname{accD} \Psi$ & $\operatorname{accD} \Psi$ & $\operatorname{accD} \Psi$ \\
\hline $\begin{array}{l}\text { 16. c-type } \\
\text { cytochrome } \\
\text { synthesis (ccs) }\end{array}$ & SSC & $\operatorname{ccs} \mathrm{A}$ & SSC: $\operatorname{ccs} A$ & SSC: $\operatorname{ccs} A$ \\
\hline $\begin{array}{l}\text { 17. Translational } \\
\text { initiation factor } \\
\text { (inf) }\end{array}$ & LSC & $\inf A$ & $\operatorname{infA}$ & $\operatorname{infA}$ \\
\hline \multirow[t]{3}{*}{$\begin{array}{l}\text { 18. Hypothetical } \\
\text { chloroplast reading } \\
\text { frames }(y c f)\end{array}$} & LSC & $\mathrm{ycf} 3, \mathrm{ycf} 4 \Psi$ & $\mathrm{ycf} 3, \mathrm{ycf} 4 \Psi * *$ & ycf3, ycf4 \\
\hline & SSC & ycf1, ycf2, ycf684 & ycf1, ycf2, ycf68 & ycf1 $\Psi$, ycf2 $\Psi$ \\
\hline & IRs & ycf2-p (2X) & ycf2-p (2X) & 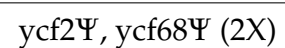 \\
\hline
\end{tabular}

$\Psi$ indicates a pseudogene. The note "- $\mathrm{p}$ " indicates that a partial DNA sequence of a gene is inserted in the two IRs. * indicates that rpl33 lacks in M. supertexta but it is present in the other three species of this structure. In addition, this gen is pseudogene in all species except in M. albiflora. ${ }^{* *}$ indicates that is a pseudogene in M. crucigera and $M$. solisioides of structure 2. ${ }^{* * *}$ indicates that it is pseudogene only in M. solisioides of structure 2 and M. pectinifera of structure 1. 


\subsection{Structure 1: Shortest IRs, Composed of Three Genes, rpl23-trnI-CAU-ycf2}

This structure was distinguished by two short IRs (of $<1 \mathrm{~kb}$ ) composed by rpl23-trnI-CAU-ycf2. Of this ycf2, a total of 265 bases of its 5' extreme are inserted in the IRs, which were identical in DNA sequence and gene composition. This structure 1 was found only in two species of Krainzia subgenus, M. albiflora, and M. pectinifera (Figure 1, Table 1). The genome of M. albiflora was larger (110,789 bp, Table 1) than the one of M. pectinifera. In this structure, both IRs had length $1348 \mathrm{bp}(1.22 \%$ of the total genome). The three genes represented $5.3 \%$ of the total genes (113). These two species had an identical number of total genes; most of which (26.6\%) were represented by tRNAs (Figure 1a, Table 1). The LSC covered the largest proportion of the DNA sequence $(72.6 \%$, Table 1$)$ and the largest number of genes (82) (Table 2). However, rpl2 gene is flaking IRA in M. pectinifera but in M. albiflora is flanking IRB that is the identical location of the species of structures 2 and 3.

\subsection{Structure 2: IRs Composed by an Unusual Complete Battery of 11 Concatenated Genes and One Identical Intergenic Spacer.}

Structure 2 was found in three species of the subgenus Mammillaria (M. crucigera, M. Huitzilopochtli, and M. supertexta) and one of the subgenus Krainzia (M. solisioides). In all of these, the two IRs were formed by genes usually located at the LSC, and were flanked by the DNA sequence of an identical intergenic spacer sequence (IGS) that is from psbk to trnQ; however, IRB was flanked by rps19, whereas IRA was flanked by $p s b K$ (Figure 1). The complete composition of this structure consisted of this IGS and 11 genes: IGS ( $p s b K-\operatorname{trn} Q)$-trnQ-UUG-rps16-trnK-UUU-matK-trnK -UUU-psbA-trnH-GUG-rpl2-rpl23-trnI-CAU-ycf2. The four species with structure 2 had identical IRs, with respect to gene composition and DNA sequence. However, there were differences between species, in terms of the total genome length, number of genes, and length of each of the four quadripartite regions (Table 1). The rpl33 gene was found in three species, but was absent in M. supertexta. Consequently, the total number of genes differed among the structure 2 species (Tables 1 and 2). Although they showed differences, the four species had similar percentages in the relative proportions of genes represented in IRs, LSC, and SSC, as well as in the percentages of gene types in the overall genome (Tables 1 and 2). Using $M$. supertexta, as a reference is important, as it had the largest genome in structure 2, showing $63 \%$ (75) of genes located at the LSC and $20.2 \%$ (24) at the SSC. In addition, each IR comprised $6.24 \%$ of the genes (11 genes and one IGS). In structure 2, the complete gene of maturase K gen (matK) is nested with trnK-UUU introns and inserted into the IRs. In this structure, $28.20 \%$ were tRNAs, followed by $13.67 \%$ in each of the suites of $r p s$ and $p s b$ subunits, $r p l$ subunits represent $8.40 \%$. Finally, the DNA regions that were represented by only one gene $(0.85 \%)$ were $a c c D, \operatorname{css} A, \operatorname{cem} A$, inf $A$, and $r b c L$ (Table 2).

\subsection{Structure 3: Largest and Divergent IRs in Which Four Ribosomal Units are Included.}

Structure 3 was only recorded in M. zephyranthoides (Figure 1c). This genome had a length of $107,343 \mathrm{bp}$ and 131 genes (Table 1). The LSC covered $62 \%$ of the total number of genes (81), the SSC had only 7 genes $(5.7 \%)$, and both IRs had 43 genes (32.8\%). In addition, each IR was approximately $14.1 \mathrm{~kb}$ in length and was comprised of genes typically located at the SSC. The IRA was composed of psbA-trnH-GUG-rpl23*-trnI-CAU-ycf2partial-ndhB-rps7-rps12-trnV-GAC-rrn16-ycf68-trnI-GAU-trnA-AGC -rrn23-rrn4.5-rrn5-trnR-ACG-trnN-GUU-ndhF-rpl32. The rpl23 is marked with an asterisk because it is absent in the IRB, thus the IRB was identical in gene composition and arrangements but was divergent. Structure 3 is distinguished by the ancestral presence of four rRNA subunits $(4.5,5,16$, and 23) in the IRs.

Pseudogenization in structure 3 was clearly identified, in that $y c f 2$ and $y c f 1$ showed incomplete DNA sequences. The former was truncated into three segments. Two of these segments were inserted into the IRS and the third one was at the SSC. These three segments added only to a total of $960 \mathrm{bp}$. The gene $y c f 1$ had $<1000 \mathrm{bp}$. Consequently, the shortening of $y c f 1$ and $y c f 2$ caused a diminished cpDNA total length (Table 1, Figure 1c). Additionally, this structure added, as pseudogenes, accd, rps18, rpl23, and one copy of rps12. 


\section{Discussion}

The three structures of cpDNA discovered in Mammillaria are novel and these have not been recorded in other eukaryote organisms. In addition, the divergent IRs (identified in structure 3) are a novel result for land plants (Embryophyta), only having otherwise been recently discovered in green algae of the order Ignatiales (Pseudoneochloris, and Chamaetrichon) [24]. These strong arrangements in the cpDNA of Mammillaria are notable with respect to the rest of caryophyllids as P. oleracea (Portulacaceae) and C. gigantea (Cactaceae), and even within Mammillaria (Figures 2 and 3). Based on the DNA sequences of chloroplasts and current biogeographic distribution, it was estimated that the suborder Portulacinae, which includes the families Cactaceae and Portulacaceae, diverged in the early Miocene (18.8-33.7 Mya). In particular, for Cactaceae, an origin of 10-19 Mya has been estimated [25]. This last estimation differs from the age of 35 Mya estimated for Cactaceae based on molecular phylogeny [23]. Accordingly, the members of Cactaceae are relatively young in the evolutionary history of Caryophyllales and, thus, the structures of cpDNA found in Mammillaria have evolved in a recent diverging process, as none of the three structures have been reported for other, older members of Caryophyllales.

Our results suggest that the structural reconfigurations of cpDNA within the family Cactaceae have occurred frequently. Particularly, such structural changes have mainly involved genes located at the flanking extremes of the LSC and, secondly, genes located at the SSC. Although deep and strong changes occurred in reconfigurations of the IRs, only few gene rearrangements and loss of genes occurred in the LSC, protecting the large blocks of genes involved in photosynthesis (Figure 2). We conclude that no single type of cpDNA structure characterizes all members of Mammillaria; however, the presence of IRs is a marked difference, with respect to the large columnar cacti species that have lost them.

In addition, our results showed that, among the tribes of the subfamily Cactoideae, there are notable structural differences in the cpDNA. The most evident is that Mammillaria (Cacteae) has IRs, as occurs in most of Caryophyllales, which were lost in Echinocereeae. We propose that the presence of IRs is the basal state in the Cactaceae family, as the presence of IRs is common in all members of Caryophyllales currently sequenced. However, we cannot ignore the possibility that IRs may be have been lost and recovered (with a new configuration) in multiple evolutionary events occurring during Cactaceae radiation. The phylogenetic relationships of the seven species based on DNA sequences (Figure 4) showed that M. albiflora (structure 1) is the closest species to columnar saguaro, however, $M$. pectinifera (structure 1) is the closest one to M. solisioides (structure 2). Unexpectedly, M. zephyranthoides (structure 3) occupied a branch that is closer to the three species of series Supertextae. These phylogenetic results should be taken with caution, since the number of species is too poor; however, it seems that the evolutionary underlying processes that have operated on the structural changes differ of those operating at the level of DNA sequences.

Tree scale: $0.001 \longmapsto$

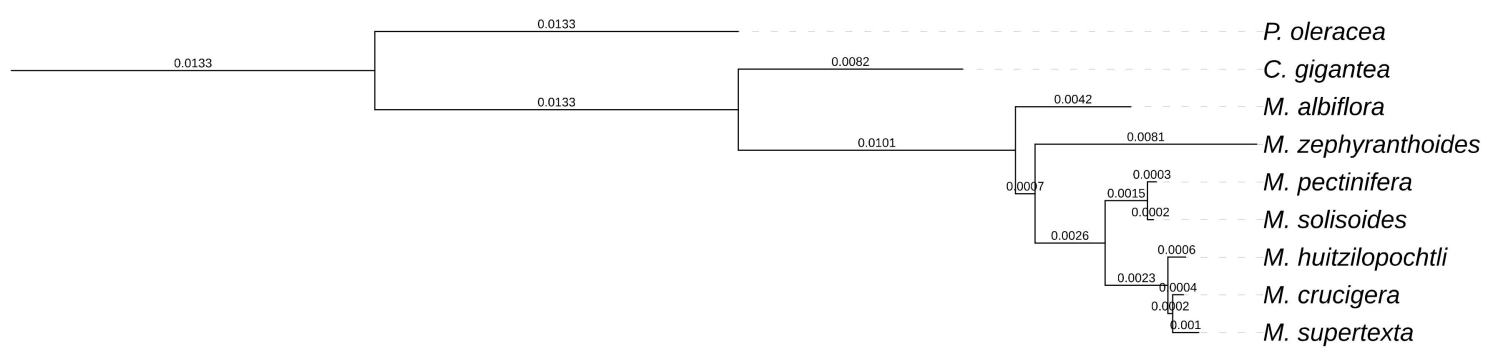

Figure 4. Phylogenetic ML tree obtained for the seven species of Mammillaria. The analysis is based on 42 coding regions shared to the two species used as outgroups (C. gigantea and P. oleraceae). 
Our findings showed that, in Mammillaria, the concatenated battery rpl23-trnI-CAU-ycf2 might have a relevant role in the reconfiguration of IRs. Particularly in these genes, it is worthy to highlight the gene trnI-CAU, which (along with trnI-GAU, trnfM-CAU, and trnM-CAU) has been identified, in experimental essays, as one of four essential tRNAs in plastids [26]. In addition, the IRs composed of a single gene have been shown to correspond to trnI-CAU (e.g. Pinus massoniana) [27]. In this context, we propose that trnI-CAU in Mammillaria plays a key role in the reconfiguration of IRs, but future studies are needed to verify this.

We found that the IGS $p s b K-\operatorname{trn} Q$ was inserted in both IRs of structure 2, although this IGS at IRB was flanked by rps19 at the LSC; meanwhile, in the rest of the species, this pair of genes ( $p s b k$ and $\operatorname{trn} Q$ ) was located at the LSC. In addition, the DNA sequence of this IGS was highly conserved, showing 91-97\% of identity to the IGS of other Caryophyllales species (e.g., C. gigantea, Cistanthe longiscaspa, Tallinum paniculatum, and P. oleracea). In addition, we found other highly conserved IGS, which

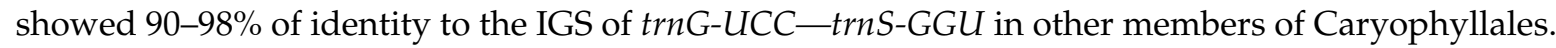
However, in Mammillaria, this pair of transfer genes was at the contrary extreme of the LSC, although the DNA sequence of this IGS was found between rpl20-rps12. Thus, we support the idea that IGS may have played an important role in the functional processes, in agreement with former studies [28]. Pseudogenization was identified in the seven species of Mammillaria, but in structure 3 it was more evident (Figures 1 and 2); particularly by the strong shortening of the genes of the two open reading frames, ycf2 and ycf1, as they had a length of $<1 \mathrm{~kb}$ whilst, in the other six species of Mammillaria, each of these genes had a length of nearly $6-7 \mathrm{~kb}$. The pseudogenization of $y c f 1$ and $y c f 2$ indicates a loss of functional activity, which disagrees with the conclusion that these genes are essential for plant survival [29]. In addition, pseudogenization was also identified for all species of Mammillaria, with incomplete copies of subunits of $r p s$ and $r p l$ suites, $a c c D$, as well as, $r p s 12$ and $c l p P$ duplicated and, evidently, in three dehydrogenase subunits (B, D, and F). These subunits translated to an interrupted sequence of amino acids, which indicates that the functionalities of these genes may have been lost. In addition, seven other subunits of $n d h$ genes were completely lost (A, C, E, H, I, J, and K). These subunits in C. gigantea, both pseudogenization and the complete loss of $n d h$ subunits in cpDNA have also been documented [12]. However, we could not show, for Mammillaria, that all of those genes documented as pseudogenes, or entirely lacking in the cpDNA, were not present in nuclear or mitochondrial genomes; in other plants, many genes of the chloroplast have been found in nuclear or mitochondrial genomes [6].

An interesting result, obtained in the SSC of the seven species of Mammillaria, C. gigantea, and $P$. schottii, is that they all have identical order and orientation of $y c f 2-t r n L-C A A-y c f 1$. This result suggests that the arrangement of these three genes may be a synapomorphy in the subfamily Cactoideae, as it is not present in Opuntia microdasys, subfamily Opuntioideae (sequence consulted GenBank: HQ664651.1), nor in the rest of the species of Caryophyllales [13].

Structure 2 was distinguished by the insertion of the matK gene into the IRs, which was nested inside of two complete $t r n K$ introns. The gene mat $K$ was also documented in the IRs of some species of Erodium (Geraniaceae) but was truncated and separated to the two trnK introns [17]. In addition, in IRs of Lamprocapnos spectabilis (Papaveraceae), complete matK nested between the two introns has been documented [30]. It is relevant to point out that matK is duplicated in these genomes due to its insertion in IRs. This encoding gene plays a fundamental role in photosynthesis by editing the RNAs of nearly 15 proteins, even though the trnK introns were lost [31]. Thus, in species having structure 2, by the formation of IRs, there are two copies of matK in the haploid genome of the chloroplast; however, we do not possess sufficient information to discuss the functional consequences of this.

Finally, it is important to point out the following: 1) the three structures of cpDNA of Mammillaria are not concordant to the taxonomic subgenera and series levels. Consequently, our results do not support any of the infrageneric classification currently proposed. 2) Sensu [18], M. solisioides is considered to be a subspecies of M. pectinifera (subgenus Krainzia, series Herrerae+Pectiniferae); however, $M$. solisioides exhibits the cpDNA structure found in the Supertextae, subgenus Mammillaria. 3) 
Accordingly, we consider that M. solisioides is an independent species, in agreement with Arias et al., [32]. We conclude that the structural analysis of cpDNA can also contribute towards clarifying the taxonomic relationships of Mammillaria with other plant species.

\section{Materials and Methods}

\subsection{Plant Sampling and DNA Extraction}

We included seven species of Mammillaria, which represent three of the eight subgenera proposed by Hunt [18]. These seven species are listed in the IUCN red list [19]. The three species sampled (M. crucigera, M. huitzilopochtli, and M. supertexta) are classified in the subgenus Mammillaria, series Supertextae. According to Crozier [21], only the species included in this subgenus represent a natural and monophyletic clade in phylogenies obtained with chloroplast DNA sequences. The other three taxa sampled (M. albiflora, M. pectinifera, and M. solisioides) are of the subgenus Krainzia, series Herrerae +Pectiniferae. It is important to mention that $M$. solisioides was considered [18] to be a subspecies of M. pectinifera. The last sampled species was M. zephyranthoides, classified in the subgenus Dolichothele. This last species has faced a complex and controversial taxonomic identification, as it has been included in both Dolichothele and Mammillaria.

Living complete plants for tissue samples were obtained for M. albiflora, M. crucigera, M. huitzilopochtli, M. pectinifera, M. solisioides, and M. supertexta. Small pieces of the surface of green stems were cleaned of spines and areoles to obtain $300 \mathrm{mg}$ samples of tissue, which were treated using a MinuteTM Chloroplast Isolation Kit (Invent Technologies Inc., Eden Prairie, MN, USA), according to the manufacturer's instructions. The chloroplast extracts were processed with a DNeasy plant minikit (Qiagen, Valencia, CA, USA), in order to obtain enriched chloroplast genomes.

\subsection{High-Throughput Sequencing and Sanger Verification}

Massive sequencing was done with the Illumina platform (Ilumina, San Diego, CA, USA). For each species, genomic libraries were prepared with the Nextera XT kit, according to the manufacturer's instructions, and sequenced in a MiSeq $2 \times 300$ cycles. The flanks of IRs and gene rearrangements were PCR verified (Table S1), using the recently assembled cpDNA in our study for the design of specific primers with Primer3 v.4 [33]. These PCR products were sequenced in a $3730 \times 1$ capillary sequencer (Applied Biosystems, Pleasanton, CA, USA).

\subsection{Genome Assembly, Annotation, and Structural Alignment}

The available assembly genome for the giant columnar cactus species of Carnegiea gigantea [12] lacks IRs and, thus, de novo assembly was carried out with NovoPlasty v.2.6.5. [34] and DISCOVAR de novo v.52488 [35]. The scaffolding was carried out with Ragout v.2.0 [36]. The gaps were filled with GARM v.0.7.5 [37] and the circularization of each of the assembly genomes was obtained with Circlator v.1.5.5 [38]. The assemblage of each genome was tested with REAPR v.1.0.18 [39]. The annotation for the seven species was done with GeSeq [40] and the genomes were drawn with OGD [41]. For gene annotation, we used the cpDNA of C. gigantea [12] and Portulaca oleracea [42]. Annotation of the largest genome found for each of the three different structures (Table 1) was manually curated. The structural alignment of the complete assembly genomes was performed with MAUVE [43]. This program was also used to compare these structures to other species of Caryophyllales (P. oleracea, NC_036236.1) and Cactaceae (C. gigantea, GCA_002740515.1), in order to emphasize the relevance of our structural findings in the whole chloroplast genome of Mammillaria. In order to reconstruct the phylogenetic relationships of the seven species of Mammillaria, two species (C. gigantea and P. oleracea) were used as outgroups. A total of 42 orthologous protein-coding genes (Table S2) shared in these nine species were identified with Prottest [44]. The DNA sequences of these 42 loci were aligned using MAFFT v7.310 [45]. The Akaike Information Criterion (AIC) in JMODELTEST v2.1.10 was used to determine 
the best-fitting model of nucleotide substitutions [46]. The GTR + G model was used to obtain the phylogenetic tree based on ML in RAXML-HPC v8.2.10 [47] with 1000 replicates.

Supplementary Materials: The following are available online at http://www.mdpi.com/2223-7747/8/10/392/s1, Table S1: Primer sequences designed for PCR verifications for flanking adjacent sequences of IRs; and gene rearrangements located at LSC in three genomes structures of Mammillaria. In the last column the temperature used to amplify each locus for all species. Primer design was based on the DNA sequences of M. albiflora (structure 1), M. supertexta (structure 2) and M. zephyranthoides (structure 3); Table S2. List of the total of 42 coding loci were used to obtain phylogenetic relationships of the seven species of Mammillaria studied and the two species used as outgroups Carnegiea gigantea and Portulaca oleraceae.

Author Contributions: S.S. is the researcher leading of this study, she designed research and obtain the financial support. S.S., S.A., and P.D. carried out fieldwork and taxonomic identification. S.S. and D.A.C. carried out chloroplasts and DNA isolation. C.E.D.-V. and F.V.-P. implemented experimental protocols of massive sequencing. A.S.-F. supervised bioinformatics analyses, which were processed by D.A.C. and K.E. A.G.-R. supervised the experiments for PCR verifications. S.S. and D.A.C. prepared the complete manuscript; and A.G.-R. and P.D. reviewed all draft versions. All the authors approved the submitted version of this this article.

Funding: This study is supported by grants from the Dirección General de Personal Académico of UNAM for research projects (DGAPA-PAPIIT IN222216).

Acknowledgments: SEMARNAT (SGPA/DGVS/06880/16) supplied sampling permission. G. Mendoza-Juárez (IIES UNAM) carried out PCR verification. L.M Marquez-Valdelamar and N.M López-Ortiz (Laboratorio de Secuenciación de LaNaBio, IB UNAM) provided sequencing service for Sanger sequencing. P. Gaytán (Unidad de Síntesis y Secuenciación de ADN, IBT UNAM) synthetized primers for PCR verification. We are grateful to Unidad de Secuenciación Masiva y Bioinformática of the Laboratorio Nacional de Apoyo Tecnológico a las Ciencias Genómicas, CONACyT \#260481, at the Instituto de Biotecnología/UNAM for advice and training in bioinformatics to Sofía Solórzano and Delil A. Chincoya. The comments of two anonymous reviewers improved the quality of this article.

Conflicts of Interest: The authors declare that the research was conducted in the absence of any commercial or financial relationships that could be construed as a potential conflict of interest.

\section{References}

1. Daniell, H.; Lin, C.S.; Yu, M.; Chang, W.J. Chloroplast genomes: Diversity, evolution, and applications in genetic engineering. Genome Biol. 2016, 17, 134. [CrossRef] [PubMed]

2. Morden, C.; Delwiche, C.; Kuhsel, M.; Palmer, D. Gene phylogenies and the endosymbiotic origin of plastids. Biosystems 1992, 28, 75-90. [CrossRef]

3. Cavalier-Smith, T. The origins of plastids. Biol. J. Linn. Soc. 1982, 17, 289-306. [CrossRef]

4. Lemieux, C.; Otis, C.; Turnel, M. Ancestral chloroplast genome in Mesostigma viride reveals an early branch of green plant evolution. Nature 2000, 403, 649-652. [CrossRef] [PubMed]

5. Xiao-Ming, Z.; Junrui, W.; Li, F.; Sha, L.; Hongbo, P.; Lan, Q.; Jing, L.; Yan, S.; Weihua, Q.; Lifang, Z.; et al. Inferring the evolutionary mechanism of the chloroplast genome size by comparing whole-chloroplast genome sequences in seed plants. Sci. Rep. 2017, 7, 1555. [CrossRef] [PubMed]

6. Thorsness, P.E.; Weber, E.R. Escape and migration of nucleic acids between chloroplasts, mitochondria, and the nucleus. Int. Rev. Cytol. 1996, 165, 207-234. [CrossRef]

7. Yagi, Y.; Shiina, T. Recent advances in the study of chloroplast gene expression and its evolution. Front. Plant Sci. 2014, 5, 61. [CrossRef]

8. Kung, S.D.; Lin, C.M. Chloroplast promoters from higher plants. Nucleic Acids Res. 1985, 13, 7543-7549. [CrossRef]

9. Mower, J.P.; Vickrey, T.L. Advances in Botanical Research Plastid Genome Evolution; Chaw, S.M., Jansen, R.K., Eds.; Academic Press of Elsevier: London, UK, 2018; Volume 85, Chapter 9; pp. 263-292.

10. Zhu, A.; Guo, W.; Sakski, G.; Weishu, F.; Mover, J.P. Evolutionary dynamics of the plastid inverted repeat: The effects of expansion, contraction, and loss of substitution rates. New Phytol. 2016, 209, 1747-1756. [CrossRef]

11. Lavin, M.; Doyle, J.J.; Palmer, J.D. Evolutionary significance of the loss of the chloroplast-DNA Inverted Repeat in the Leguminosae Subfamily Papilionoideae. Evolution 1990, 44, 390-402. [CrossRef]

12. Sanderson, M.J.; Copetti, D.; Búrquez, A.; Bustamante, E.; Charboneau, J.L.M.; Eguiarte, L.; Kumar, S.; Lee, H.O.; McMahon, M.; Steele, K.; et al. Exceptional reduction of the plastid genome of saguaro cactus (Carnegiea gigantea). Am. J. Bot. 2015, 102, 1115-1127. [CrossRef] [PubMed] 
13. Yao, G.; Jin, J.J.; Li, H.T.; Yang, J.B.; Mandala, V.S.; Croley, M.; Mostow, R.; Douglas, N.A.; Chase, M.W.; Christenhusz, M.J.M.; et al. Plastid phylogenomic insights into the evolution of Caryophyllales. Mol. Phylogenet. Evol. 2019, 134, 74-86. [CrossRef] [PubMed]

14. Huang, H.; Shi, C.; Liu, Y.; Mao, S.Y.; Gao, L.Z. Thirteen Camellia chloroplast genome sequences determined by high-throughput sequencing: Genome structure and phylogenetic relationships. BMC Evol. Biol. 2014, 14, 151. [CrossRef] [PubMed]

15. Wu, Z.; Tembrock, L.R. Two complete chloroplast genomes of white campion (Silene latifolia) from male and female individuals. Mitochondrial DNA Part A 2015, 28, 375-376. [CrossRef]

16. Kang, J.S.; Lee, B.Y.; Kwak, M. The complete chloroplast genome sequences of Lychnis wilfordii and Silene capitata and comparative analyses with other Caryophyllaceae genomes. PLoS ONE 2017, 27, e0172924. [CrossRef] [PubMed]

17. Blazier, J.C.; Jansen, R.K.; Mower, J.P.; Govindu, M.; Zhang, J.; Weng, M.L.; Ruhlman, T.A. Variable presence of the inverted repeat and plastome stability in Erodium. Ann. Bot. 2016, 117, 1209-1220. [CrossRef]

18. Hunt, D.; Taylor, N.; Charles, G. The New Cactus Lexicon; DH Books: Milborne Port, UK, 2006.

19. IUCN International Union for Conservation of Nature. Consulted for Mammillaria genus. Available online: https://www.iucnredlist.org/search/list?query=Mammillaria\&searchType=species (accessed on 30 June 2019).

20. Butterworth, C.A.; Wallace, R.S. Phylogenetic studies of Mammillaria (Cactaceae)-Insights from chloroplast sequence variation and hypothesis testing using the parametric bootstrap. Am. J. Bot. 2004, 91, 1086-1098. [CrossRef] [PubMed]

21. Crozier, B.S. Systematics of Cactaceae Juss: Phylogeny, cpDNA Evolution, and Classification, with Emphasis on the Genus Mammillaria Haw. Ph.D. Thesis, University of Texas, Austin, TX, USA, 2005.

22. Hernández-Hernández, T.; Hernández,H.M.; De Nova, J.A.; Puente, R.; Eguiarte, L.; Magallón, S. Phylogenetic relationships and evolution of growth form in Cactaceae (Caryophyllales, Eudicotyledoneae). Am. J. Bot. 2011, 98, 44-61. [CrossRef]

23. Arakaki, M.; Christin, P.A.; Nyffeler, R.; Lendel, A.; Eggli, U.; Ogburn, M.; Spriggs, E.; Moore, M.J.; Edwards, E.J. Contemporaneous and recent radiations of the world's major succulent plant lineages. Proc. Natl. Acad. Sci. USA 2011, 108, 8379-8384. [CrossRef]

24. Turmel, M.; Otis, C.; Lemieux, C. Divergent copies of the large inverted repeat in the chloroplast genomes of ulvophycean green algae. Sci. Rep. 2017, 7, 994. [CrossRef]

25. Ocampo, G.; Columbus, J.T. Molecular phylogenetics of suborder Cactineae (Caryophyllales), including insight into photosynthetic diversification and historical biogeography. Am. J. Bot. 2010, 97, 1827-1847. [CrossRef] [PubMed]

26. Alkatib, S.; Fleischmann, T.T.; Scharff, L.B.; Bock, R. Evolutionary constraints on the plastid tRNA set decoding methionine and isoleucine. Nucleic Acid Res. 2012, 40, 6713-6724. [CrossRef] [PubMed]

27. Ni, Z.; Ye, Y.; Bal, T.; Xu, M.; Xu, L.A. Complete chloroplast genome of Pinus massoniana (Pinaceae): Gene rearrangements, loss of ndh genes, and short inverted repeats contraction, expansion. Molecules 2017, 22, 1528. [CrossRef]

28. Hao, D.C.; Chen, S.L.; Huang, B.L. Evolution of the chloroplast trnL-trnF region in the Gymnosperm lineages Taxaceae and Cephalotaxaceae. Biochem. Genet. 2009, 47, 351-369. [CrossRef] [PubMed]

29. Drescher, A.; Ruf, S.; Calsa, T., Jr.; Carrer, H.; Bock, R. The two largest chloroplast genome-encoded open reading frames of higher plants are essential genes. Plant J. 2000, 22, 97-104. [CrossRef] [PubMed]

30. Park, S.; An, B.; Park, S. Reconfiguration of the plastid genome in Lamprocapnos spectabilis: IR boundary shifting, inversion, and intraspecific variation. Sci. Rep. 2018, 8, 13568. [CrossRef] [PubMed]

31. Barthet, M.M.; Hilu, K.W. Expression of matK: Functional and evolutionary implications. Am. J. Bot. 2007, 94, 1402-1412. [CrossRef]

32. Arias, S.; Gama-López, S.; Guzmán-Cruz, L.U.; Vázquez-Benítez, B. Cactaceae. In Flora del Valle de Tehuacán-Cuicatlán; Medina, L.R., Ed.; Instituto de Biología, Universidad Nacional Autónoma de México: Mexico City, Mexico, 2012; Volume 95.

33. Rozen, S.; Skaletsky, H. Primer3 on the WWW for general users and for biologist programmers. Methods Mol. Biol. 2000, 132, 365-386. [CrossRef]

34. Dierckxsens, N.; Mardulyn, P.; Smits, G. NOVOPlasty: De novo assembly of organelle genomes from whole genome data. Nucleic Acids Res. 2017, 45, e18. [CrossRef] 
35. Love, R.R.; Weisenfeld, N.I.; Jaffe, D.B.; Besansky, N.J.; Neafsey, D.E. Evaluation of DISCOVAR de novo using a mosquito simple for cost-effective short-read genome assembly. BMC Genom. 2016, 17, 18. [CrossRef]

36. Kolmogorov, M.; Raney, B.; Paten, B.; Pham, S. Ragout-a reference-assisted assembly tool for bacterial genomes. Bioinformatics 2014, 30, i302-i309. [CrossRef] [PubMed]

37. Soto-Jiménez, L.M.; Estrada, K.; Sanchez-Flores, A. GARM: Genome assembly, reconciliation and merging pipeline. Curr. Top. Med. Chem. 2014, 14, 418-424. [CrossRef] [PubMed]

38. Hunt, M.; De Sila, N.; Otto, T.D.; Parkhill, J.; Keane, J.A.; Harris, S.R. Circlator: Automated circularization of genome assemblies using long sequencing reads. Genome Biol. 2015, 16, 294. [CrossRef] [PubMed]

39. Hunt, M.; Kikuchi, T.; Sanders, M.; Newbold, C.; Berriman, M.; Otto, T.D. REAPR: A universal tool for genome assembly evaluation. Genome Biol. 2013, 14, R47. [CrossRef] [PubMed]

40. Tillich, M.; Lehwark, P.; Pellizzer, T.; Ulbricht-Jones, E.S.; Fischer, A.; Bock, R.; Greiner, S. GeSeq-versatile and accurate annotation of organelle genomes. Nucleic Acids Res. 2017, 45, W6-W11. [CrossRef] [PubMed]

41. Lohse, M.; Drechsel, O.; Bock, R. OrganellarGenomeDRAW (OGDRAW): A tool for the easy generation of high-quality custom graphical maps of plastid and mitochondrial genomes. Curr. Genet. 2007, 52, 267-274. [CrossRef]

42. Liu, X.; Yang, H.; Zhao, J.; Zhou, B.; Li, T.; Xiang, B. The complete chloroplast genome sequence of the folk medicinal and vegetable plant purslane (Portulaca oleracea L.). J. Hortic. Sci. Biotech. 2018, 93, 356-365. [CrossRef]

43. Darling, A.C.; Mau, B.; Blattner, F.R.; Perna, N.T. Mauve: Multiple alignment of conserved genomic sequence with rearrangements. Genome Res. 2004, 14, 1394-1403. [CrossRef]

44. Darriba, D.; Taboada, G.L.; Doallo, R.; Posada, D. ProtTest 3: Fast selection of best-fit models of protein evolution. Bioinformatics 2011, 27, 1164-1165. [CrossRef]

45. Katoh, K.; Daron, M.S. MAFFT multiple sequence alignment software version 7: Improvements in performance and usability. Mol. Biol. Evol. 2013, 30, 772-780. [CrossRef]

46. Posada, D. JModelTest: Phylogenetic model averaging. Mol. Biol. Evol. 2008, 25, 1253-1256. [CrossRef] [PubMed]

47. Stamatakis, A. RAxML version 8: A tool for phylogenetic analysis and post-analysis of large phylogenies. Bioinformatics 2014, 30, 1312-1313. [CrossRef] [PubMed]

(C) 2019 by the authors. Licensee MDPI, Basel, Switzerland. This article is an open access article distributed under the terms and conditions of the Creative Commons Attribution (CC BY) license (http://creativecommons.org/licenses/by/4.0/). 